\title{
Research on Audit Data Analysis under the Background of Big Data
}

\author{
Li Zhang* \\ Academy of Accounting, Guangzhou Huashang College, Guangzhou 511300, China
}

*Corresponding author: Li Zhang, baobif713517@163.com

\begin{abstract}
With the arrival of the era of big data, the audit thinking mode has been promoted to change. Under the influence of big data, audit will become an activity of continuous behavior. Through cloud data, the staff can control the operation status and risk assessment of the whole enterprise, timely analyze, control and respond to risks, and protect the enterprise to reduce risks. With the advent of the era of big data, audit data analysis is becoming more and more important. At the same time, a large amount of data analysis also brings challenges to auditors. Methods to deal and solve the challenges has become an urgent problem to be solved at present. This paper mainly studies the challenges and countermeasures brought by the changes of audit approaches and methods to audit data analysis under the background of big data, so as to continuously innovate and practice the improvement of audit technology and promote the healthy and rapid development of social economy.
\end{abstract}

Keywords: Big data; Audit data analysis; Research

Publication date: May 2021; Online publication: May 31, 2021

\section{Introduction}

In 2020, the Ministry of Industry and Information Technology will issue the relevant guidance on the development of big data, making a comprehensive deployment to promote the deep integration of big data and enterprise development, and proposing to strengthen data convergence, sharing, application, governance and security to promote industrial development. In this context, major enterprises have carried out digital transformation and upgrading, breaking the original business model, we will comprehensively develop information technology and big data. Big data is the general trend of the development of informatization. With the development of the comprehensive informatization of the auditee, the demand for audit data analysis and processing is on the rise greatly. As a comprehensive economic supervision department, audit will certainly face great challenges under the background of big data.

Big data refers to the storage and calculation of a large number of changeable terminal data through information storage and analysis based on cloud computing, which is characterized by large quantity, variety and speed. With the combination of big data and audit, continuous audit will become a reality. Auditors can use cloud data to grasp the changes of company operations and risks, timely analyze and warn internal risks, control and eliminate risks and hidden dangers, which can produce good social utility. Under the background of big data, audit data analysis should actively adapt to and comprehensively serve the needs of current economic development. However, in the use and analysis of data, it is bound to face a series of problems. How to solve these problems has become an urgent problem to be solved at present. On the basis of the challenges to traditional auditing in the context of big data, this paper intends to explore the ways and methods of auditing in the mode of big data, mainly analyzing the problems and solutions in the analysis and use of audit data, so as to deal with the opportunities and challenges brought by the development of The Times, which has a certain realistic research value. 


\section{What is Big Data and Audit Data Analysis}

Big data refers to a data set whose size exceeds the acquisition, storage, management and analysis capabilities of conventional database tools, but it does not mean that a data set with a specific TB value must be considered as big data (McKinsey, 2011). Big data has 4V characteristics, such as Volume of data, rapid data flow, Velocity of dynamic data system, Variety of data types and huge data Value.

At present, the production and business activities of enterprises are more active, forming a large number of data and information covering a large number of contents. Big data technology can provide cross-field, cross-time and cross-space quantifiable massive data for audit work, so that a large number of relevant audit information can be recorded and analyzed. Big data audit based on the analysis of more complex large unstructured data analysis, such as association rule mining, clustering analysis, genetic algorithms, machine learning, and according to different data types of cross analysis, semantic analysis, graphic transformation, speech recognition, completely broke the traditional descriptive analysis and reporting, has strong flexibility is more suitable for the comprehensive analysis, The adoption of big data analysis mode can obtain deep information and improve the utilization rate and value of data information.

\section{The impact of big data on audit analysis}

\subsection{Change the thinking mode of audit analysis}

The arrival of big data has led to changes in audit thinking mode. Compared with traditional audit thinking mode, it relies more on audit sampling mode and lacks the ability to obtain, process and analyze all data. At the same time, traditional audit is limited by time and place. For example: the uncertainty of confirmation time; The inquiry is limited to the employee's working hours; Due to the limited time and economic cost of the audit work to and from different cities on the site, a variety of constraints lead to the inability to carry out the audit work flexibly. Big data allows audit work to be free from time and place restrictions. Auditors obtain all required data through cloud records, view the relevant data of the audited entity and the transaction records of the corresponding entity through authority, and judge the authenticity and accuracy of data information.

Big data can make full use of computers to obtain huge data through auditing software. Computer software can be used for screening and selection, and useful information can be found in a short time according to different auditing purposes. The combination of manual and machine can make the control range of auditing wider, and the time span can be effectively improved. With the application of information technology, the information obtained by auditors has changed from the original manual vouchers to the big data with high generality. Auditors are required to transform the audit mode into a model combining big data analysis and spot check based on the data.

\subsection{Improve the accuracy of data analysis}

With the support of big data, audit data is based on data transmission, which greatly improves the accuracy of data, ensures the overall and orderly transmission of follow-up data, and improves the value and communication of data itself. When obtaining audit evidence, the causal logic relationship is based on the traditional way of thinking. However, big data will make more use of correlation analysis, reduce the dependence of traditional auditors on the causal logic relationship, better discover suspicious points and help to accurately expose illegal acts, so as to make the audit conclusion more accurate. Big data records and stores the transaction behavior data generated by enterprise operation in different subsystems, leaving "footprints," and reproduces and simulates the transaction operation scene of enterprises through central data integration and classification, so that there is no hiding place for all kinds of transactions of enterprises. These "footprints" not only provide legal protection to enterprises, but also provide a strong deterrent to illegal and criminal activities, which can ensure the accuracy of audit. 


\subsection{Reduce analysis cost and improve analysis efficiency}

With the continuous progress of information technology, the data quantity changes from terabyte level to zettabyte level, which promotes the stream processing mode to replace the batch processing mode gradually. Through the use of models and software, it can help auditors to obtain and capture valuable information, realize real-time analysis, help auditors to find and solve problems in the audit in the first time, and improve the efficiency of audit work. Through the full use of data mining, it can carry out classified mining on the scattered mass data, effectively evaluate the operation situation of enterprises and make targeted comparison, improve the timeliness of audit and the authority of audit analysis. In the context of big data, auditors can better audit based on the actual situation of big data, reduce audit costs, and at the same time make full and effective use of data mining, cloud database, distributed structure, network audit and other innovative and diversified technical means to constantly improve audit efficiency.

\subsection{Improve the convenience of data acquisition}

Scrutiny under the background of big data, can use computer as an audit tool, increase the accuracy, time, scope and transaction records from the bank, the enterprise transaction business trading records, etc. These actions by the government authorized, screening the effective information from a single site audit innovation as the on-site audit and remote audit, improve the work quality, convenient data acquisition.

\section{Problems faced by audit analysis in the context of big data}

\subsection{The reliability of audit data is low}

In the computer auditing environment, the data is stored in magnetic medium, and the information needed for analysis can only be called out from the computer system through man-machine dialogue. In the process of data generation, there are many artificial manipulation links, and different units will generate different data formats due to the use of different software. In the process of data collection, auditors cannot determine the authenticity of the data and the conversion of different data formats produces unforeseeable errors, which leads to the increase of audit risks.

\subsection{The analysis method of audit data is backward}

Although computers have infiltrated into all areas of audit work, most of them are still in the statistical analysis of data or online inquiry of laws and regulations, information, etc., and the application degree of computer analysis is still low. Data analysis technology is difficult to master, and the effective integration of big data analysis method and audit limits the development of big data audit.

\subsection{Network security is difficult to guarantee}

The era of big data not only brings explosive growth of information, but also puts forward higher standard requirements for information security. Audit data often involves confidential or internal information of the auditee. How to ensure data security and prevent data leakage are also the key issues to be solved in big data audit. The security of audit data is likely to lead to the following problems. First, the software system is not safe, and it cannot ensure the stability and fluency of the core information software and the accuracy and uniformity of the files. Second, the environment of the computer room is not safe, and the related hardware facilities of the data room are the basis to ensure the construction of audit information, so the security and network security of the computer room must be guaranteed. Third, the database is not safe, did not do a good job of database system firewall and authority configuration work.

\subsection{Auditors lack IT technology and big data thinking}

The use of the new audit methods also has new constraints on the requirements of auditors, which requires 
a compound high-quality audit team. It is emphasized that auditors should not only master relevant knowledge of accounting and audit, but also have a certain comprehensive ability of information technology (IT), big data and cloud computing. The audit industry relies more on "experience-driven business" and lacks the research and development of analysis models based on its own characteristics. It also lacks the mastery of "data-driven" analysis technologies such as association rule classification, crowdsourcing, data fusion, data mining and analysis technologies, cloud computing, data warehouse and other visualization technologies. Currently, auditors have solid professional skills in auditing, but lack systematic learning of computing information technology knowledge, big data auditing thinking, and data processing and analysis ability. Traditional auditors still rely more on audit experience. Without changing the thinking of big data analysis, audit work cannot keep up with the pace of the era of big data.

\section{Countermeasures and Suggestions}

\subsection{Accelerate the implementation and implementation of relevant audit systems}

Under the background of new era requires new counter measures, in combination with the characteristics of the era of big data design reasonable auditing theory, establish and improve the response to new information technology environment audit laws and regulations, the audit staff put forward new career requires that the power and responsibility in the process of auditing and data confidentiality work put forward the corresponding rules and regulations and laws, ensure the authenticity of the data collection. For the government, while encouraging enterprise informatization, it should also guide the development of audit under the background of big data from the legal level. For the audit department, it is necessary to make a data reserve plan to eliminate the "information island" and establish a perfect audit data center. For the IT industry, IT is necessary to understand the audit department's demand points for big data and solve the integration of software services.

\subsection{Ensure data security}

Data explosion era, data security problems will follow, a large number of data leakage is bound to cause unfair phenomenon to the social economy. To solve the problem of data security, to prevent data loss, hacker attacks, systems and data tampering brings new audit risk, audit personnel should strengthen the sense of confidentiality, take corresponding safety precautions, such as audit electronic data to apply computer technology to identify the authenticity of electronic data, check whether there is a computer data system vulnerability, set up an inspection team to regularly evaluate the safety factor of the internal system. Auditors also need to improve IT security governance and compliance at the same time, do a good job in the construction of firewall and audit authority, privilege prevention, leak prevention, attack prevention, from the inner network to the outer network identity authentication and authorization to prevent abuse of authority control, ensure information security and infrastructure security.

\subsection{Establish database and audit data analysis platform}

Audit institutions need to comprehensively enhance the construction of information engineering, improve the processing ability of audit data, attach importance to information collection, and establish a unified and standardized industrial database. Big data is the beginning of the progress of IT industry, IT become the new engine for social economic growth, is a new integration and restructuring the traditional organization structure, and the big data only after information gathering, classification and correlation can realize its value, at present because the auditees financial behavior is not standard auditors from more than one way to get the audit data, content is not the real problem, In order to hinder the matching and association of data, we should establish a database, strengthen the related research on audit practice and audit theory, and construct a big data linkage audit mechanism with aggregation effect, which is led by the government, 
promoted by audit and participated by IT industry.

Our country enterprise itself hard to meet the large data storage and operation, need the government out of the relevant support policy for the enterprise equipped with large storage performance excellent multi-function software and hardware equipment, the establishment of national government level crossindustry audit data platform, establish good audit software selection mechanism, the audit innovation technology with outstanding contribution award rewards, to encourage technological innovation, Accelerate the application and implementation of audit technology.

\subsection{Cultivate versatile talents and establish a professional analysis team}

China's big data audit started late, accounting staff knowledge structure is not comprehensive, the lack of understanding and use of big data and the habit of traditional audit mode will hinder the recognition of new audit methods, only experience and a single verification of data will inevitably increase the risk of audit. At the same time, under the current background of big data, it is difficult to reduce audit risks without big data and the direction of social progress. On the premise of paying close attention to hardware facilities, accounting firms also need to strengthen staff training and improve CPA's ability of big data audit analysis in many aspects. Auditors need to cultivate the vision of big data, improve the data index system, accelerate knowledge innovation, enhance the practical ability of audit staff to cope with the development, improve the construction of audit team and cultivate compound audit talents, so as to provide guarantee for the development and utilization of data.

In the future, the data faced by auditors will grow exponentially, which puts forward new requirements for the data processing and data analysis ability of auditors. Traditional auditors should gradually change from relying on audit experience to relying on data analysis, so that the audit work can keep up with the pace of the era of big data. Auditing departments should train auditors to study computers and data information as part of their daily training. The firm can also build a professional analysis team, establish a simple and visual data analysis system, visually and conveniently present the audit analysis method, process and results, copy the successful test, and quickly improve the audit data analysis ability. Firms should pay attention to the cultivation of corporate data culture, the formation of auditors' data literacy, and the cultivation of data as a "second language."

\section{6. the conclusion}

Under the background of big data, many innovative and diversified data technologies will continue to emerge. Audit work will continue to change and innovation, from the traditional means to cloud database, network data mining, distributed structure, the use of these various methods make the amount of data, data types, data processing methods have undergone significant changes. Under the background of such changes, auditors are faced with the challenge of changing from audit mode to audit method and method to adapt to the future. In the era of big data, auditors should set up the consciousness of "data first," establish the idea of data core, make full use of data analysis function to identify risks and improve efficiency, and combine data analysis with on-site investigation to better implement audit work. Big data will become the new power of human economic construction, and it is undeniable that the audit work has also ushered in new opportunities and challenges. On this basis, we should analyze the current situation, continue to innovate practices, and promote the healthy and rapid development of social economy.

\section{Funding}

Key Major of Audit Science in quality Engineering Project of Private Universities in 2020 (Grant No. : HS2020ZLGC06), Supervisor System Research Project of Huashang College of Guangdong University of Finance and Economics in 2018 (Grant No. : 2018HSDS03), University Quality Engineering of 
Huashang College in 2021 (Grant No. : HS2021ZLGC19)

\section{Disclosure statement}

The author declares no conflict of interest.

\section{References}

[1] Cui Z, 2021, Innovative Application of Data Analysis Technology Method in Enterprise Audit. Journal of Finance and Accounting, 4(07):82-88.

[2] Zhu, Cai, Li, et al., 2019, A Research on the Application of Big Data in Auditing. International Journal of Audit Management, 17 (1): 1-9.

[3] Tang K, 2018, Impact on Audit in the Era of Big Data. Communications World, (08).

[4] Zhang Z, Cheng X, 2017, Auditing Data Analysis Framework Based on Text Mining in Big Data Environment. Friends of Accounting, (16):117-120.

[5] Zhu L, 2016, Research on the Influence of Big Data and Cloud Technology on the Full Coverage of Audit Supervision. Journal of Audit, (05).

[6] Gu H, 2015, Preliminary Study on Audit Data Analysis Technology under Big Data Environment. China Management Informatization, (03):45-47.

[7] Wang Q, 2015, Analysis of Audit Data in Big Data Environment. China Audit News,2015-1230(006).

[8] Qin R, 2014, Research on the Impact of Big Data and Cloud Computing Technology on Audit. Audit Research, (06). 